\title{
Do Pathogenic Chronic Infections Cause Host Senescence?
}

\author{
Aline Scovino ${ }^{1}$, Aryanne Trigueiros ${ }^{1}$ and Alexandre Morrot ${ }^{1,2 *}$ \\ ${ }^{1}$ Laboratório de Imunoparasitologia, Instituto Oswaldo Cruz, Fiocruz, Rio de Janeiro, Brazil \\ ${ }^{2}$ Centro de Pesquisas em Tuberculose, Instituto de Microbiologia, Faculdade de Medicina, Universidade Federal do Rio de Janeiro, Rio de Janeiro, Brazil
}

${ }^{\star}$ Corresponding author: Alexandre Morrot, Laboratório de Imunoparasitologia, Instituto Oswaldo Cruz, Fiocruz, Rio de Janeiro, Brazil; E-mail: alexandre.morrot@ioc. fiocruz.br, alexandre.morrot@medicina.ufrj.br

Received: May 14, 2021; Accepted: May 25, 2021; Published: May 29, 2021

Aging and senescence are words used as synonyms, and refer to the progressive and deleterious changes that occur in cells, tissues and organs, which alter their functionality [1]. In complex multicellular organisms such as animals, aging begins as soon as embryonic development reaches its maximum stage of differentiation. Aging cannot solely be explained by telomere shortening optics, but rather a combination of factors,including protein assembly and packaging errors, somatic mutations and errors in DNA repair, free radicals, reactive oxygen species, and epigenetic modifications such as hypermethylation [2]. Through molecular control, cells in their maximum state of differentiation stop dividing or reduce their cell division rates. Even tissues of intense proliferation accumulate mutagenic events, whether by environmental factors, by pathogenic infection, or by the events described above that stimulate senescence. Physiologically, our body uses strategies to eliminate senescent cells, damaged cells, or are able to recycle malformed organelles or proteins without the need for cellular elimination. Through autophagy or the removal of senescent cells by the immune system, our body prevents the accumulation of these cells, thus controlling, for example, the growth of tumors ${ }^{3}$. This is why there is a higher incidence of tumors in the elderly [3].

Through the action of NK cells and $\mathrm{CD}^{+} \mathrm{T}$ cells, the immune system is able to eliminate any cells whose surface protein expression indicates signs of damage and/or malignant transformation. During senescence, there is a significant reduction in the ability of immune cells to fight pathogens, leading to chronic infection [4]. A classic example of senescent cell control and elimination is the red blood cells. Mature red blood cells are anucleated cells whose half-life is approximately 115 days. After this period they become senescent, with the gradual deterioration of their capacity, and they are subsequently eliminated in the spleen. Red blood cells have surface molecules that signal their state of senescence, indicating the right time to eliminate them. The formation of band 3 protein aggregates (one of the most abundant red cell transmembrane proteins), when stabilized by oxidized hemoglobin molecules (hemichromes), are recognized as antigens by autologous IgG antibodies and complement system. With the deposition of a critical density of antibodies and complement molecules, senescent red blood cells are recognized and eliminated [5].
The senescent red blood cells expose phosphatidylserine on the outer portion of their plasma membrane, a sign that indicates that the cell should be phagocytosed. In healthy cells this phospholipid is actively maintained in the cytoplasmic portion of the plasma membrane. Concomitantly, there is down-regulation of the CD47 molecule, a transmembrane protein whose normal expression indicates a non-phagocytic signal. The exposure of phosphatidylserine coupled with the reduction of CD47 expression stimulates phagocytosis and the elimination of these red blood cells [6]. In 2001, Bratosin [7] and colleagues described a process similar to apoptosis occurring in red blood cells, later called erythrosis [8]. Eryptosis has several similarities to apoptosis, regardless of the trigger, induction of an eripotic state usually involves extracellular calcium entry into the cell, caspase and calpain activation, which causes changes in membrane asymmetry, phosphatidylserine exposure and cell shrinkage. and membrane. Erythrosis has been associated with several pathologies, including metabolic syndromes, uremic syndromes, anemias such as sickle cell anemia and thalassemia, and can be triggered by several signs, including osmotic shock and xenobiotics [5].

Infectious processes also induce erythrosis, such as Plasmodium infection that cause malaria [5]. Infection with $P$. falciparum induces oxidative stress, promoting the opening of calcium channels. Erythrosis also appears to be induced in uninfected red blood cells, both in P. yoelii [9] and P. falciparum infections [10]. That is, chronic infection during malaria induces early red blood cell senescence. Autophagy is a physiological mechanism that allows cells to recognize damaged proteins or organelles and destroy them. In situations of mitochondrial stress, such as the increase of reactive oxygen species, autophagic processes may induce apoptosis cell death [11]. Autophagy also participates in the protection against some intracellular pathogens, although some are able to escape phagolysosome degradation. The relationship between autophagy and senescence is that the latter is characterized precisely by cells resistant to apoptosis and whose autophagic processes do not occur [12].

Like malaria, other chronic infections can also induce host aging. Some bacteria, viruses and protozoa are capable of causing tissue stress leading to molecular and physiological changes in host cells leading to a senescence process. In individuals with cystic fibrosis caused by 
Pseudomonas aeruginosa, it is believed that the pyocyanin bacterial toxin prevents autophagy. This is due to the increased production of reactive oxygen species, preventing the scaling of the pulmonary epithelium and thus facilitating bacterial colonization [13]. Furthermore, chronic infection with Chlamydia trachomatis, induces increased DNA methylation, and consequently senescence [14].

In infection with Mycobacterium tuberculosis, it is believed that autophagy would function as a protective factor against infection, representing an efficient antimicrobial factor. Although the bacterial toxin ESAT-6 inhibits autophagosome maturation, it is believed that inhibition of autophagy is an activated factor of senescence, so factors that induce autophagosome maturation, such as IFN-gamma, would be inhibitors of senescenia [3]. Coinfection between $M$. tuberculosis and HIV induces high viremia and functionally altered $\mathrm{CD}^{+} \mathrm{T}$ lymphocytes, which are associated with increased expression of cellular markers associated with this characteristic, as well as the absence of other activation factors such as perforins, granzymes and intracellular IFN-gamma [15].

This state of Tlymphocytes is compatible with immunosenescence, which is the aging of the immune system that can be caused by chronic infections, such as HIV, Plasmodium spp., or also by tumors [16]. As with M. tuberculosis infection, Trypanosoma cruzi infection is another example of a chronic infection that induces host senescence related to autophagy blockade [17]. In Chagas disease, we observed lymphopenia and signs of T-cell senescence. In patients infected with T. cruzi, $\mathrm{CD}^{+}$and $\mathrm{CD} 4^{+} \mathrm{T}$ cells display markers of immunosensitivity and show a depleted functional phenotype with decreased production of IFN-gamma and IL-23. Along with evasion of the immune system, T. cruzi can also prevent autophageal intracellular degradation by compromising autophagosome maturation. Autophagy blockade contributes, as the protection of cellular stress, to the activation of senescence [3].

\section{References}

1. Balcombe N, Sinclair A (2001) Ageing: definitions, mechanisms and the magnitude of the problem. Best Pract Res Clin Gastroenterol 15: 835-849. [crossref]
2. Teixeira INDO, Guariento ME (2010) Biology of aging: theories, mechanisms, and perspectives. Ciênc. Saúde Coletiva 15: 6

3. Aguilera MO, Delgui LR, Romano PS, Colombo MI (2018) Chronic Infections: A Possible Scenario for Autophagy and Senescence Cross-Talk. Cells 7: 162. [crossref]

4. Franceschi C, Bonafe M, Valensin S, Olivieri F, De Luca M, et al. (2007) Inflammaging and anti-inflammaging: a systemic perspective on aging asd longevity emerged from studies in humans. Mech Ageing Dev 128: 92-105. [crossref]

5. Lang F and Qadri SM (2012) Mechanisms and Significance of Eryptosis, the Suicidal Death of Erythrocytes. Blood Purif 33: 125-30. [crossref]

6. Boulet C, Doering CD, Carvalho TG (2018) Manipulating eryptosis of human red blood cells: a nnovel antimalaraial strategy? Frontiers in Cellular and Infection Microbiology 8: 1-18. [crossref]

7. Bratosin D, Estaquier J, Petit F, Arnoult D, Quatannens B, et al. (2001) Programmed cell death in mature erythrocytes: a model for investigating death effector pathways operating in the absence of mitochondria. Cell Death Differ 8: 1143-1156. [crossref]

8. Lang K, Lang P, Bauer C, Duranton C, Wieder T, Huber S, et al. (2005) Mechanisms of suicidal erythrocyte death. CPB 15: 195-202. [crossref]

9. Totino PRR, Pina RA, De-Oliveira ACAX, Banic DM, Daniel-Ribeiro CT, et al. (2013) Apoptosis of non-parasitised red blood cells in Plasmodium yoelii malaria. Mem Inst Oswaldo Cruz 108: 686-690. [crossref]

10. Totino PRR, Magalhães AD, Silva LA, Banic DM, Daniel-Ribeiro CT, et al. (2010) Apoptosis of non-parasitized red blood cells in malaria: a putative mechanism involved in the pathogenesis of anaemia. Malar J 9: 350. [crossref]

11. Dikic I (2007) Proteasomal and Autophagic Degradation Systems. Annu. Rev. Biochem 86: 193-224.

12. Campisi J, D’Adda Di Fagagna F (2007) Cellular senescence: When bad things happen to good cells. Nat. Rev. Mol. Cell Biol 8: 729-740. [crossref]

13. Luciani A, Villella VR, Esposito S, Brunetti-Pierri N, Medina D, et al. (2010) Defective CFTR induces aggresome formation and lung inflammation in cystic fibrosis through ROS-mediated autophagy inhibition. Nat. Cell Biol 12: 863-875. [crossref]

14. Kessler M, Hoffmann K, Fritsche K, Brinkmann V, Mollenkopf H-J, et al. (2019) Chlamydia infection in human organoids increases stemness and promotes agedependent CpG methylation. Nature Communications 10: 1194. [crossref]

15. Barathan M, Mohamed R, Vadivelu J, Chang LY, Vignesh R, et al. (2017) CD8 ${ }^{+}$T cells of chronic HCV-infected patients express multiple negative immune checkpoints following stimulation with HCV peptides. Cell. Immunol 313: 1-9. [crossref]

16. Chou JP, Effros RB (2013) T Cell Replicative Senescence in Human Aging. Current Pharmaceutical Design 19: 1680-1698. [crossref]

17. Onizuka Y, Takahashi C, Uematsu A, Shinjo S, Seto E, et al. (2017) 1. Inhibition of autolysosome formation in host autophagy by Trypanosoma cruzi infection. Acta Trop 170: 57-62. [crossref]

\section{Citation:}

Scovino A, Trigueiros A, Morrot A (2021) Do Pathogenic Chronic Infections Cause Host Senescence? Trends in Vaccines and Immunology Volume 1(2): 1-2. 